\title{
Digital Twin (DT) in Smart Energy Systems - Systematic Literature Review of DT as a growing solution for Energy Internet of the Things (EloT)
}

\author{
Ali Aghazadeh Ardebili, *, Antonella Longo,, Antonio Ficarella \\ SyDa Lab, CRISR, Department of Engineering for Innovation, University of Salento, 73100 (LE), \\ Lecce, Italy
}

\begin{abstract}
In the industry 4.0 era, the Smart Energy System (SES) should be able to address the emerging challenges of digitization and socioeconomic/ecologic transition along with other critical entities of the society. However, because of the complexity of this system, both researchers and practitioners are seeking an agile and smart solution. The main motive of this review is to investigate the applications and implementation of Digital Twin (DT) in the provision of energy services. Research Questions (RQ) of this study include: RQ1: What are the applications of DT in SES and how effective is DT in that use case of EIoT? RQ2: Which issues of an SES can be addressed efficiently by using DT? Through answering the mentioned questions, the current study is heading to following objectives $(\mathrm{O}), \mathrm{O} 1$ : Describe the state of the art of DT in SES. O2: Develop a direction for energy 4.0 management through listing the applications, challenges and important factors of implementing DTs. O3: Provide a list of various approaches in employing DT in the scope of SES. The current study is a systematic literature review (SLR), based on SCOPUS, WOS and IEEE digital libraries. Two keywords (namely "Digital Twin" and "Energy Systems") have been first used. To achieve the final list of articles, 2 levels of screening have been conducted. The first Screening was based on the relevance of the results concerning research objectives. The second screening was an abstract study. The exclusion/inclusion criteria in the abstract study were based on the research questions. The papers that have the potential of answering one of the research questions have been included. Since the implementation of DT is a rather new topic, both backward snowballing and forward snowballing strategies are implemented to finalize the article selection phase. 60 articles identified by searching through scientific databases and 11 articles have been appended to the list during the snowballing process. The results of the current review provide a managerial guideline for practitioners that are heading to utilize DT, along with an anthology of DT within SES scope to feed possible future studies.

Keywords: Digital Twin, Energy System, Smart Energy System, Power Systems, Energy Internet of the Things, Internet of the Things, Industry 4.0
\end{abstract}


Acronyms: Digital Twin (DT), Energy Systems (ES), Smart Energy System (SES), Energy Internet of the Things (EIoT), Internet of the Things (IoT), Cyber-Physic-Social Systems (CPSS), Artificial Intelligence (AI), Machine Learning (ML), Decision Support System (DSS), Phasor Measurement Unit (PMU), intermittent renewable energy sources (IRES), Virtual Energy Storage (VES), Virtual Energy Storage System(VESS), Internet Protocol (IP), Human-Machine Interface (HMI), Machine to Machine (MtoM), Communicational artificial intelligence (AI) Mean (C-AI-M), finite element methods (FEM), computational fluid dynamics (CFD), Graphical User Interface (GUI), Historical Recording and Database (DB), State Estimation (SE), Model Data Management (MDM), Contingency Analysis (CA), Static Security Assessment (SSA), Power Flow (PF), Short Circuit Current (SCC), Wide Area Monitoring, Protection and Control (WAM, WAP and WAC), Dynamic Security Assessment (DSA), Phasor Data Processing (PDP), Protection Security Assessment (PSA), System Integrity Protection Schemes (SIPS), Dynamic State Estimation (DSE)

\section{Introduction}

Industrial systems are the backbone of economy [1-3]. However, economic activities within industrial domain are providing societies with opportunities and risks at the same time [4-7]. These risks are mainly menace environment, and society members. Since current study domain is energy systems, we take energy production supply chain as an example. Considering traditional energy production, the power plants need fossil fuel to produce energy. Extracting fossil fuels and mining is a contaminant technology [8-11]. Transporting the fuel causes $\mathrm{CO} 2$ emission and other environmental contaminations by means of transport [12-14]. And finally, the customers demand has a direct influence on the necessity of production amount in which effect the volume of previously mentioned environmental risks. The whole system components are usually in real-time communication to make decisions and IT technology facilitate this communication means $[15,16]$. This is the reason to consider Energy System as Cyber-Physic-Social Systems (CPSS). In such a system, the individual entities should work as a whole to decrease the socio-ecologic risks of entire system.

On the other hand, competitiveness of the markets is increasing, and producers are imposed to necessity of increasing efficiency and decreasing costs. Natural disasters threats are crucial in this sector. Since Energy Systems (ES) should continuously stay in action to provide society with a vital consumable, ES is counted as critical entity [17]. Therefore, its security and safety matter. All these facts caused the raise of the necessity of making the ES Sustainable and Resilient [18]. The industry 4.0 provided a solution to guarantee the Sustainability and Resilience of the ES [19-22].

The fourth industrial evolution of ES resulted in developing Smart Energy System (SES). In such a smart system, the sensors collect data and send to centralised Decision Support System (DSS). DSS uses Artificial Intelligence (AI) and Machine Learning (ML) algorithms to make crucial real-time decisions. Machine-to-Machine communications facilitate the DSS to send commands to the machineries and control actuators to place the orders. IoT has further enhanced the capabilities of decision making starting from sensing physical entities [23-25]. In SES specific domain it is called EIoT[26-28]. To bring the decisions of DSS in action a new concept introduced as Digital Twin, which includes the digital replica of entire system (both Cyber side and Physical entities)[29-31]. Nevertheless, Digital Twin (DT) is yet under study and not practically mature. This is the main reason of current study to identify the potentials, gaps and applications of DT to empower EIoT. The main objectives $(\mathrm{O})$ of this study are set in 3 directions: O1: Describe the state of the art of DT in SES. O2: Envision some directions for energy 4.0 management 
through listing the applications, challenges and important factors of implementing DTs. O3: Provide a list of various approaches in employing DT in the scope of SES. To reach the objectives two Research Questions (RQ) are considered as following:

- RQ1: What are the applications of DT in SES and how effective is DT in that use case of EIoT?

- RQ2: Which issues of an SES can be addressed efficiently by using DT?

Then General Literature review has been done to provide knowledge on main concepts and finally a Systematic Literature Review SLR has been performed to extract the answer for research questions from existing literature. In the following subsections, the three main concepts SES, EIoT and DT are introduced. Then the Methodology of SLR will be explained in detail. In Section 3 the results of SLR will be reported and discussed. Finally, the conclusion of current study is listed in Section 4.

Table 1. Setting Word's margins.

\begin{tabular}{|c|c|}
\hline Margin & $\mathbf{m m}$ \\
\hline Top & 24 \\
\hline Bottom & 16 \\
\hline Left & 20 \\
\hline Right & 20 \\
\hline
\end{tabular}

\subsection{Smart Energy System in Literature}

Energy providing systems include both electricity and thermal energy types. The systems that provide this energy resources are vital for a society to function properly[32]. So, it is crucial to increase the reliability of energy production, transmission and distribution chain. To control the cost of the whole system, the efficiency of the components and entire system should be maximized. On the other hand, most of the energy has been still producing in combustion-based plants [33]. Therefore, in traditional energy production plans, the optimization of process is important to reduce the emission and fossil fuel consumption [34].

Looking from cutting edge technology lens, different aspects of energy systems can improve. Taking advantage of renewable energy resource is sharply increasing [35]. The price of energy forced many end users to provide simple renewable energy plant for their individual uses[36]. Tremendous resources are ongoing on energy storage technologies. And last but yet important, new energy sources and technologies are developing. Considering all of these aspects, physical models of the energy systems are very complex. And the complexity increases when the novel concepts are brought in practice like Virtual Energy Systems [37,38], Hybrid Production[39-41], Multi directional energy production[42] etc. Physical models are incapable effectively used for monitoring, control, and manage these complex systems. In this situation, AI comes in action and data-driven models are used to make the system autonomous, and efficient to function [43].

Smart Energy Systems (SES) are complex energy systems which lay operations on datadriven models. For instance, the data are provided by EIoT system and smart sensing systems like Phasor Measurement Unit (PMU) [26,44].

In SES energy can flow in both directions from main energy producer to energy grid and to individual users, or from individual users as small producer to the main grid. In this case a building with a solar panel can take the energy from the main grid and sell the 
energy to main grid when the production of solar panel is more than the consumption in the building [45-47]. The bidirectional flow of the energy is controlled by a control center which is the brain of the whole system and make it smart.

On the other hand, the production of renewable energy is fluctuating because of the nature of renewable resources. In some cases, because of high oscillation, intermittent renewable energy sources (IRES) are not usable [48]. But scheduling and predictions that a smart system makes, provides the possibility of take advantage of a big part of renewable energies which are non-dispatchable without the support of artificial intelligence. SES also facilitate the traditional Energy Storage and Virtual Energy Storage (VS) concept in practice [49-52]. Without help of AI, planning for virtual storage and energy retrieve from VES System (VESS) is very laborious in small scale and impossible in big scale[52-54].

\subsection{EloT in Literature}

Energy Internet of things (EIoT) is a application of Internet of things (IoT) in energy systems. Similar to its parent technology (IoT), EIoT is a complex system that has CyberPhysical-Social System (CPSS) components [55-58]. In EIoT, the Thing is a physical set that operates in order to provide a service or product. Physical entities of EIoT include all machineries, actuators, computers and even incorporated sensors[59]. The physical entities are in uninterrupted communication. This communication is facilitated by internet through assigning an Internet Protocol address (IP) to the things [60,61]. The data transmitted on the network are collected by sensors and it is about the state of the thing, or command signals to set an order to machine and actuate a function[61]. These orders are decisions made by data-driven DSS and AI algorithms. The software is the brain of the system and the cyber part of CPSS. This kind of communication is Machine to Machine (MtoM) communication. But the CPSS need to be administered and controlled by operators. So, the system needs Human-Machine Interface (HMI). On the other side, the end user's energy consumption needs to be taken in consideration in decisions. AI plays the demand prediction role too [62-66]. The end user's consumption patterns play the exert social effect in CPSS.

EIoT of State Grid Corporation of China, and EU-funded Sharing Cities project (SHARING CITIES) applied in England (Greenwich) are examples of bringing EIoT in action[67,68]. Despite, the researchers and practitioners try to bring EIoT in action but still there are big challenges in practice and some researchers question the feasibility of IoT in such a complex system.

The cost of the sensors in such a big system is very high. Some of these sensors needs high initial investment and even if self-optimizing sensors are growing, still many sensors need regular checks and periodic calibrations $[69,70]$. Connectivity is the biggest challenge that researchers are trying to deal with. Real time simulation of system needs high speed data transfer and very powerful algorithms to execute data-driven models and machine learning algorithms using big data, and powerful processors and hardware to handle the computations[71-74].

Integrating the system and using cloud platforms is an efficient way to place the cyber parts of EIoT but could usage have its own risks too[75-77]. On the other hand, ML usage is very delicate approach particularly in critical infrastructures. An example of issues derived from data-driven models' usage are problems with biased data [78]. Regarding the authors experience, the available data in ES is usually the data created during the system's functioning. Moreover we face with lack of data in case of failures. Using such a database can cause problem during training the ML algorithms[79-81]. The last but yet important challenge of EIOT is the lack of Communicational artificial intelligence (AI) Mean (C-AI$\mathrm{M})$. In IoT we can see the advancements in Conversational artificial intelligence (AI) like 
Alexa, Cortana, and Siri. But in industrial milieu, particularly in ES, no CAIM has been developed, and possible HMIs are under study.

\subsection{Digital Twin in Literature}

Digital Twin (DT) is a virtual reproduction of a physical entity. It is used in NASA for first time to design the spacecrafts. There is no common definition of Digital Twin in the literature; however, in the following we will mention the most cited definitions.

In manufacturing sector, DT implementation is growing sharply. Grieve claim DT in manufacturing has three main elements: physical entity, its virtual representative and the data. Data is the pivot point that connect the physical and virtual entity [82,83]. Its application is in product design and smart manufacturing[84-86]. For instance, in lifetime and fault prediction in a aircraft, DT uses probabilistic data as input and finite element methods (FEM) and computational fluid dynamics (CFD) to predict the behavior of Physical entity[86-90].

Notwithstanding, in other applications, the predictions are based on big data analytics $[85,91,92]$. In Systems Engineering and particularly Cyber-Physical Systems the common general definition is slightly different and emphasize the synchronized link between two entities. The definitions that highlight the data analytics is reported in Tab. 1.

Table 1 The Selected definitions of Digital Twin according to the scope and application

\begin{tabular}{|c|l|c|}
\hline $\begin{array}{c}\text { Scope } \\
\text { Application }\end{array}$ & \multicolumn{1}{|c|}{ Definition } & Ref. \\
\hline \multirow{2}{*}{ Manufacturing } & $\begin{array}{l}\text { "DT is very realistic models of the current state of the } \\
\text { process and their own behavior in interaction with their } \\
\text { environment in the real world" }\end{array}$ & {$[93]$} \\
\hline \multirow{2}{*}{$\begin{array}{c}\text { Data-Oriented } \\
\text { modeling }\end{array}$} & $\begin{array}{l}\text { "Coupled model of the real machine that operates in the } \\
\text { cloud platform and simulates the health condition with an } \\
\text { integrated knowledge from both data driven analytical } \\
\text { algorithms as well as other available physical knowledge" }\end{array}$ & {$[94]$} \\
\hline \multirow{2}{*}{$\begin{array}{c}\text { Systems } \\
\text { Cyber-Physical }\end{array}$} & $\begin{array}{l}\text { "Digital Twin, which links the physical system with its } \\
\text { virtual equivalent can mitigate these problematic issues" }\end{array}$ & {$[95]$} \\
\cline { 2 - 4 } & $\begin{array}{l}\text { "The Digital Twin (DT) is meant as the virtual and } \\
\text { computerized counterpart of a physical system that can be } \\
\text { time synchronization of the sensed data coming from the } \\
\text { field" }\end{array}$ & {$[96]$} \\
\cline { 2 - 4 } & "Digital Twin, requires a cloud-based solution to ensure a \\
\end{tabular}

Different applications are reported for DT in literature, life prediction [86], supply chain simulation [99], safety and reliability [30], quality control/improve [100], maintenance [101-105], urban administration [106], building lifecycle [107,108], uncertainty management [95], decision science [109], material science [110], cloth industry [111], 
project management [112], robotics [113,114], sustainable development [115,116]. However, in current study will focus on Energy systems. Energy system is a kind of complex system which also count as a critical infrastructure of a nation.

\section{Methodology}

The current study is a systematic literature review (SLR). After defining research questions, advanced strings are employed to search related articles in digital libraries. The digital libraries used in this SLR are including SCOPUS, Google Scholar, Web of Science, and IEEE. Then during SLR process, empirical evidences extracted and summarized regarding pre-specified eligibility criteria. The process of performing this SLR is as following:

1. Setting the scope of the study and main objectives -Three main objectives O1-3 are listed in introduction-.

2. Setting the Research Questions-Four main objectives RQ1-4 are listed in introduction-.

3. Choose the scientific databases to perform the primary search.

4. Choose keywords regarding the RQs and scope.

5. Set inclusion criteria as following:

a. Only English Documents

b. Peer Reviewed Documents

c. Full Articles, Books, Reviews

d. Articles that pregnant for potential answer for the RQs

6. Create research queries and make the primary list of articles. (70 articles selected-After duplication check 60 articles remained)

7. First Screening: Abstract read (13 article excluded)

8. Second Screening: full paper Skimming (21 article excluded)

9. Snow balling: forward and backward (11 articles was added to list)

10. Full paper deep read of the articles to collect information. (37 articles)

Regarding the above-mentioned process, Step 1 and 2 is detailed in introduction. The advanced search in step 6 provided 70 articles searching through the digital libraries that are selected in Step 3 and the keywords that are identified in Step 4. After duplication check reduced to 60 articles. Then in Step 7, abstract screening, 13 article excluded from the list regarding the relevance of topic to the research questions of this study. In second screening phase 21 article is excluded using the criteria that is set in Step 5. 11 articles added to the list employing snowballing technic (both Forward and Backward snowballing). The final list of articles include 37 articles which is used to collect eve3idence based data to answer research questions.

\section{Results and Discussion}

\subsection{RQ1_Applications and Impact}

Fig. 1 shows the applications of DT that mentioned in the literature in SES domain. The categories of applications are defined during the full paper read of the articles as follows: During full paper read phase of SLR, the main application of the DT in the article is extracted; if it was in the list of applications that previous articles mentioned already, the number of the articles in this category is increased one; if the application is not mentioned in previous applications, we added the application to the list of categories. The most popular application of DT is anomaly detection and after that the smart grid management 
and control, dynamic monitoring of the system, and demand forecast are the frequent applications of DT. Anomaly detection is the most sought-after application of the DT.

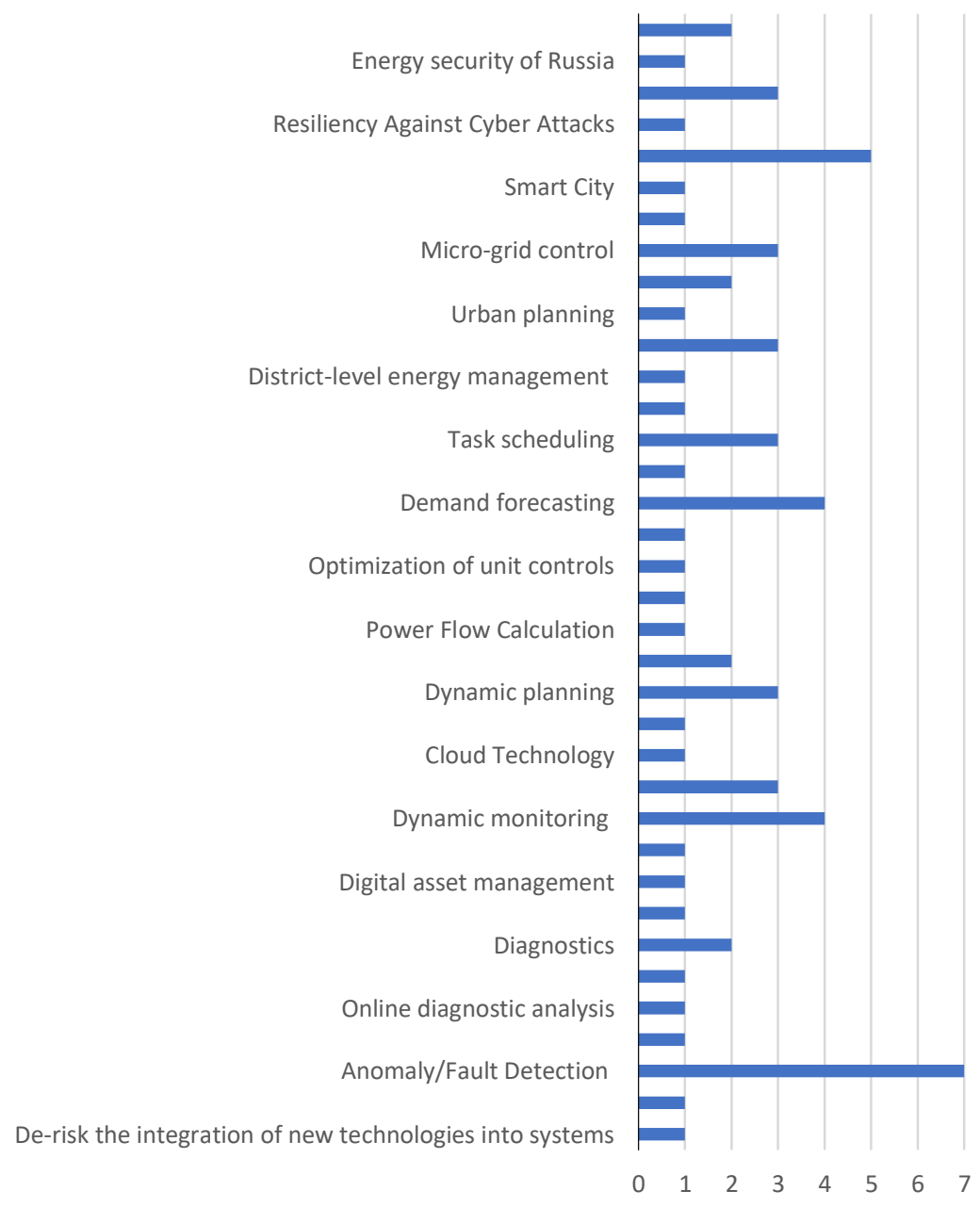

Fig. 1 Applications of DT in SES

Monitoring the system operation is crucial to evaluate the systems performance [117]. System health monitoring is utilized in wind turbines [118], buildings [119], and batteries [120]. Dynamic monitoring is a particular application of DTs. In this use cases, DT is coupled with SCADA. DT uses the data and perform statistical analysis through data stream assessment. Finally, it will provide a DT based monitoring system in control rooms [121]. To be more precise, even if the articles directly speak about system monitoring, the main goal of the dynamic monitoring is also anomaly detection [117]. Dynamic monitoring observes the system continuously in real time by receiving and analyzing data from sensors. This real time monitoring cycle facilitates by digital thread, which represents data from sensors, information from system and the flow of this information between physical and virtual entities. This aspect is very important for constructing efficient EIoT[117]. On the other hand DT provides online monitoring possibility which supports the EIoT concept in practice in SES [122]. 
In the final list multiple articles highlight applications of DT in smart grids [68,123130]. In fact, smart grid is an energy infrastructure. So, it is crucial to investigate it closely. These articles mostly point out the following goals for using DT in a smart grid:

- Load Balancing

- Power Management

- Optimized Task Scheduling

- Consumer Services

- Fault Identification, Diagnosing

- Demand Forecasting

- Power Monitoring System (PMS)

Within the above-mentioned applications to empower the smart grids, demand forecast is the most frequent application. This result shows that DT plays the role of brain of the system. At the same time, it can provide information through HMI for decision makers as a Decision Support Tool.

\subsection{RQ2_Solutions provided by DT}

Modern monitoring systems fulfill new needs in smart systems. DT can succor modern monitoring systems to deal with cutting edge technologies. DT can provide efficient solutions to deal with the complexity of systems[68,123,131-137,137] thanks to the development of processes, elements, analysis, and methods. The main topics in the field are related to:

1. SCADA and Graphical User Interface (GUI)

2. Historical Recording and Database (DB)

3. State Estimation (SE)

4. Model Data Management (MDM)

5. Contingency Analysis (CA)

6. Static Security Assessment (SSA)

7. Power Flow (PF)

8. Short Circuit Current (SCC)

9. Operational Planning Tools,

10. Demand Forecasts

11. Wide Area Monitoring, Protection and Control (WAM, WAP and WAC),

12. Dynamic Security Assessment (DSA),

13. Phasor Data Processing (PDP),

14. Protection Security Assessment (PSA),

15. System Integrity Protection Schemes (SIPS)

16. Dynamic State Estimation (DSE)

\section{Conclusion}

The results show that DT furnish the system to stablish a network of interrelated physical and virtual entities to automate the system. In other words, DT makes the energy system smart and provides a dynamic monitoring on whole system including the information flow between the components. The most frequent applications of DT in SES, including anomaly detection and demand forecast, unveil the capability of DT to contribute in decision making. So in parallel to monitoring, DT provides a DSS for the SES that facilitate control communication and automated functioning of SES. In the use cases, the communication through internet is implemented. This connection provides a real-time monitoring and 
response. Therefore, we can conclude that in smart energy systems, Digital Twin is a solution to push the EIoT in action. In our future agenda there is the development of a model including users (i.e. customers, actors) in a digital twin framework in order to implement DT as a cyber-physical social system model.

Current article is a primary step of detailed review on the Digital Twin cutting edge technology in Smart Energy Systems. Future study will focus on technical advancements of DT in order to detail the data-oriented modeling in DT, Architectures and model frameworks that DT employs to improve the resilience of a Smart Energy System.

\section{References}

- The authors, in the form: initials of the first names followed by last name (only the first letter capitalized with full stops after the initials),

- The journal title (abbreviated),

- The volume number (bold type),

- The article number or the page numbers,

- The year of publication (in brackets).

Authors should use the forms shown in Table 3 in the final reference list.

Table 3. Font styles for a reference.

\begin{tabular}{|c|c|}
\hline Element & Style \\
\hline Authors & $\begin{array}{c}\text { Normal } \\
\text { Initials followed by last name }\end{array}$ \\
\hline Journal title & $\begin{array}{c}\text { Normal } \\
\text { Abbreviated }\end{array}$ \\
\hline $\begin{array}{c}\text { Book title, } \\
\text { Proceedings title }\end{array}$ & Italic \\
\hline Volume number & Bold \\
\hline Page number & Normal \\
\hline Year & $\begin{array}{c}\text { Normal } \\
\text { In brackets }\end{array}$ \\
\hline
\end{tabular}

1. N. Cetorelli and M. Gambera, "Banking Market Structure, Financial Dependence and Growth: International Evidence from Industry Data," J. Finance, vol. 56, no. 2, pp. 617-648, Apr. (2001), doi: 10.1111/0022-1082.00339.

2. D. L. Kay, J. E. Pratt, and M. E. Warner, "Role of Services in Regional Economy Growth," Growth Change, vol. 38, no. 3, pp. 419-442, Sep. (2007), doi: 10.1111/j.1468-2257.2007.00377.x.

3. P. A. Stone, "Building economy. Third edition,” Jan. (1983), Accessed: Jun. 10, 2021. Online. Available: https://www.osti.gov/biblio/6025338

4. A. Aghazadeh Ardebili and E. Padoano, "Change assessment aims to transition to green service-case study of quantitative Risky-Opportunity analysis in a PSP Company," in Second International Conference on Sustainable Production and Consumption: Explore interactions between technology, the environment, economy, society and policy, (2020) 
5. T. M. Hoag and C. F. Lemme, "Animal-Derived Food Industry: Risks And Opportunities Due To Farm Animal Welfare," Rev. Adm. Empres., vol. 58, pp. 244 253, Jun. (2018) doi: 10.1590/S0034-759020180305.

6. R. Janssen and D. D. Rutz, "Sustainability of biofuels in Latin America: Risks and opportunities," Energy Policy, vol. 39, no. 10, pp. 5717-5725, Oct. (2011), doi: 10.1016/j.enpol.2011.01.047.

7. V. der Zee and L. Francois, "Modelling of electricity cost risks and opportunities in the gold mining industry," Thesis, (2014). Accessed: Jun. 10, 2021. Online. Available: https://repository.nwu.ac.za/handle/10394/12267

8. T. Bakke, J. Klungsøyr, and S. Sanni, "Environmental impacts of produced water and drilling waste discharges from the Norwegian offshore petroleum industry," Mar. Environ. Res., vol. 92, pp. 154-169, Dec. (2013), doi: 10.1016/j.marenvres.13.09.012.

9. R. Flin, K. Mearns, M. Fleming, and R. Gordon, "Risk perception and safety in the offshore oil and gas industry," Nov. (1996), Accessed: Jun. 10, 2021. Online. Available: https://www.osti.gov/etdeweb/biblio/383507

10. A. MacIntosh, K. Dafforn, B. Penrose, A. Chariton, and T. Cresswell, "Ecotoxicological effects of decommissioning offshore petroleum infrastructure: A systematic review," Crit. Rev. Environ. Sci. Technol., vol. 0, no. 0, pp. 1-39, May (2021), doi: 10.1080/10643389.2021.1917949.

11. O. J. Tveit, B. J. Myklatun, T. J. Bohler, and O. J. Vesterhaug, "Risk Analysis Of Atypical North Sea Petroleum Production Platform," in All Days, Houston, Texas, May (1980), p. OTC-3905-MS. doi: 10.4043/3905-MS.

12. 12 D. A. Hensher and K. J. Button, Eds., Handbook of Transport and the Environment, vol. 4. Emerald Group Publishing Limited, (2003). doi: 10.1108/9781786359513.

13. T. R. Lakshmanan and X. Han, "Factors underlying transportation $\mathrm{CO} 2$ emissions in the U.S.A.: A decomposition analysis," Transp. Res. Part Transp. Environ., vol. 2, no. 1, pp. 1-15, Mar. (1997), doi: 10.1016/S1361-9209(96)00011-9.

14. Y. F. Zhang, X. Z. Gong, Z. H. Wang, and Y. Liu, "Environment Impact of Freight Transportation in China," Mater. Sci. Forum, vol. 787, pp. 144-151, (2014), doi: 10.4028/www.scientific.net/MSF.787.144.

15. T. V. Nguyen, P. Petit, F. Maufay, M. Aillerie, and J.-P. Charles, "Powerline Communication (PLC) on HVDC Bus in a Renewable Energy System," Energy Procedia, vol. 36, pp. 657-666, Jan. (2013), doi: 10.1016/j.egypro.2013.07.076.

16. H. Guozhen, C. tao, C. Changsong, and D. Shanxu, "Solutions for SCADA system communication reliability in photovoltaic power plants," in 2009 IEEE 6th International Power Electronics and Motion Control Conference, May (2009), pp. 2482-2485. doi: 10.1109/IPEMC.2009.5157821.

17. J. Augutis, B. Jokšas, R. Krikštolaitis, and R. Urbonas, "The assessment technology of energy critical infrastructure,” Appl. Energy, vol. 162, pp. 1494-1504, Jan. (2016), doi: 10.1016/j.apenergy.2015.02.079.

18. A. Aghazadeh Ardebili and E. Padoano, "A Literature Review of the Concepts of Resilience and Sustainability in Group Decision-Making," Sustainability, vol. 12, no. 7, p. 2602, Mar. (2020), doi: 10.3390/su12072602.

19. D. Ivanov, "New Drivers for Supply Chain Structural Dynamics and Resilience: Sustainability, Industry 4.0, Self-Adaptation," in Structural Dynamics and Resilience in Supply Chain Risk Management, D. Ivanov, Ed. Cham: Springer International Publishing, (2018), pp. 293-313. doi: 10.1007/978-3-319-69305-7_10.

20. M. S. Mubarik et al., "Resilience and cleaner production in industry 4.0: Role of supply chain mapping and visibility," J. Clean. Prod., vol. 292, p. 126058, Apr. (2021), doi: 10.1016/j.jclepro.2021.126058. 
21. G. Marcucci, S. Antomarioni, F. E. Ciarapica, and M. Bevilacqua, "The impact of Operations and IT-related Industry 4.0 key technologies on organizational resilience," Prod. Plan. Control, pp. 1-15, Jan. (2021), doi: 10.1080/09537287.2021.1874702.

22. P. Ralston and J. Blackhurst, "Industry 4.0 and resilience in the supply chain: a driver of capability enhancement or capability loss?," Int. J. Prod. Res., vol. 58, no. 16, pp. 5006-5019, Aug. (2020), doi: 10.1080/00207543.2020.1736724.

23. J. Gubbi, R. Buyya, S. Marusic, and M. Palaniswami, "Internet of Things (IoT): A vision, architectural elements, and future directions," Future Gener. Comput. Syst., vol. 29, no. 7, pp. 1645-1660, Sep. (2013), doi: 10.1016/j.future.2013.01.010.

24. S. Krčo, B. Pokrić, and F. Carrez, "Designing IoT architecture(s): A European perspective," in 2014 IEEE World Forum on Internet of Things (WF-IoT), Mar. (2014), pp. 79-84. doi: 10.1109/WF-IoT.2014.6803124.

25. R. van Kranenburg and A. Bassi, "IoT Challenges," Commun. Mob. Comput., vol. 1, no. 1, p. 9, Nov. (2012), doi: 10.1186/2192-1121-1-9.

26. S. O. Muhanji, A. E. Flint, and A. M. Farid, eIoT: The Development of the Energy Internet of Things in Energy Infrastructure. Springer Nature, (2019). Accessed: Jun. 10, (2021). Online. Available: https://library.oapen.org/handle/20.500.12657/22898

27. S. O. Muhanji, A. E. Flint, and A. M. Farid, "eIoT as a Solution to EnergyManagement Change Drivers," in eIoT: The Development of the Energy Internet of Things in Energy Infrastructure, S. O. Muhanji, A. E. Flint, and A. M. Farid, Eds. Cham: Springer International Publishing, (2019), pp. 1-15. doi: 10.1007/978-3-03010427-6_1.

28. S. O. Muhanji, A. E. Flint, and A. M. Farid, "Transactive Energy Applications of eIoT," in eIoT: The Development of the Energy Internet of Things in Energy Infrastructure, S. O. Muhanji, A. E. Flint, and A. M. Farid, Eds. Cham: Springer International Publishing, (2019), pp. 91-113. doi: 10.1007/978-3-030-10427-6_4.

29. C. Semeraro, M. Lezoche, H. Panetto, and M. Dassisti, "Digital twin paradigm: A systematic literature review," Comput. Ind., vol. 130, p. 103469, Sep. (2021), doi: 10.1016/j.compind.2021.103469.

30. E. Glaessgen and D. Stargel, "The Digital Twin Paradigm for Future NASA and U.S. Air Force Vehicles," in 53rd AIAA/ASME/ASCE/AHS/ASC Structures, Structural Dynamics and Materials Conference, American Institute of Aeronautics and Astronautics. doi: 10.2514/6.2012-1818.

31. The Digital Twin Paradigm for Smarter Systems and Environments: The Industry Use Cases. Academic Press, (2020).

32. A. Lamba, "Protecting 'Cybersecurity \&amp; Resiliency' of Nation's Critical Infrastructure - Energy, Oil \&amp; Gas," SSRN Electron. J., (2018), doi: $10.2139 / \mathrm{ssrn} .3535434$.

33. J. L. Sawin, "Fossil Fuel Use Up," in Vital Signs 2003-2004, Routledge, (2003).

34. K. Vohra, A. Vodonos, J. Schwartz, E. A. Marais, M. P. Sulprizio, and L. J. Mickley, "Global mortality from outdoor fine particle pollution generated by fossil fuel combustion: Results from GEOS-Chem," Environ. Res., vol. 195, p. 110754, Apr. (2021), doi: 10.1016/j.envres.2021.110754.

35. Y. Yang, H. S. Solgaard, and W. Haider, "Wind, hydro or mixed renewable energy source: Preference for electricity products when the share of renewable energy increases," Energy Policy, vol. 97, pp. 521-531, Oct. (2016), doi: 10.1016/j.enpol.2016.07.030.

36. J. D. Moss, “Solar Panels, Tax Incentives, and Your House," Probate Prop., vol. 24, p. 17, (2010). 
37. M. Cheng, S. S. Sami, and J. Wu, "Benefits of using virtual energy storage system for power system frequency response," Appl. Energy, vol. 194, pp. 376-385, May (2017), doi: 10.1016/j.apenergy.2016.06.113.

38. M. Cheng, S. S. Sami, and J. Wu, "Virtual Energy Storage System for Smart Grids," Energy Procedia, vol. 88, pp. 436-442, Jun. (2016), doi: 10.1016/j.egypro.2016.06.021.

39. M. T. Iqbal, "Modeling and control of a wind fuel cell hybrid energy system," Renew. Energy, vol. 28, no. 2, pp. 223-237, Feb.(2003), doi: 10.1016/S0960-1481(02)00016-2.

40. J. J. Ding and J. S. Buckeridge, "Design Considerations for a Sustainable Hybrid Energy System," Trans. Inst. Prof. Eng. N. Z. Civ. Eng. Sect., Nov. (2000), Accessed: Jun. 11 2021. Online. Available: https://search.informit.org/doi/abs/10.3316/INFORMIT.403268692365109

41. C. V. Nayar, S. J. Phillips, W. L. James, T. L. Pryor, and D. Remmer, "Novel wind/diesel/battery hybrid energy system," Sol. Energy, vol. 51, no. 1, pp. 65-78, Jul. (1993), doi: 10.1016/0038-092X(93)90043-N.

42. I. COLAK, R. BAYINDIR, and S. SAGIROGLU, "The Effects of the Smart Grid System on the National Grids," in 2020 8th International Conference on Smart Grid (icSmartGrid), Jun. (2020), pp. 122-126. doi: 10.1109/icSmartGrid49881.2020.9144891.

43. L. R. Gorjão et al., "Data-Driven Model of the Power-Grid Frequency Dynamics," IEEE Access, vol. 8, pp. 43082-43097, (2020), doi: 10.1109/ACCESS.2020.2967834.

44. L. A. Kumar and S. Karthikeyan, "Modeling of Phasor Measurement Unit for Wide Area Monitoring and control of Smart Grids with Distributed Energy Resources," in 2016 IEEE Conference on Technologies for Sustainability (SusTech), Oct. (2016), pp. 188-194. doi: 10.1109/SusTech.2016.7897165.

45. A. K. Verma, B. Singh, D. T. Shahani, and C. Jain, "Grid-interfaced Solar Photovoltaic Smart Building with Bidirectional Power Flow Between Grid and Electric Vehicle with Improved Power Quality," Electr. Power Compon. Syst., vol. 44, no. 5, pp. 480-494, Mar. (2016), doi: 10.1080/15325008.2015.1120818.

46. M. K. Rafique et al., "An Intelligent Hybrid Energy Management System for a Smart House Considering Bidirectional Power Flow and Various EV Charging Techniques," Appl. Sci., vol. 9, no. 8, Art. no. 8, Jan. (2019), doi: 10.3390/app9081658.

47. S. Saponara, R. Saletti, and L. Mihet-Popa, "Hybrid Micro-Grids Exploiting Renewables Sources, Battery Energy Storages, and Bi-Directional Converters," Appl. Sci., vol. 9, no. 22, Art. no. 22, Jan. (2019), doi: 10.3390/app9224973.

48. K. Ashenayi and R. Ramakumar, "IRES-A program to design integrated renewable energy systems," Energy, vol. 15, no. 12, pp. 1143-1152, Dec. (1990), doi: 10.1016/0360-5442(90)90105-B.

49. H. Zsiborács et al., "Intermittent Renewable Energy Sources: The Role of Energy Storage in the European Power System of 2040," Electronics, vol. 8, no. 7, Art. no. 7, Jul. (2019), doi: 10.3390/electronics8070729.

50. J. P. Barton and D. G. Infield, "Energy storage and its use with intermittent renewable energy," IEEE Trans. Energy Convers., vol. 19, no. 2, pp. 441-448, Jun. (2004), doi: 10.1109/TEC.2003.822305.

51. J. Joe, J. Dong, J. Munk, T. Kuruganti, and B. Cui, "Virtual storage capability of residential buildings for sustainable smart city via model-based predictive control," Sustain. Cities Soc., vol. 64, p. 102491, Jan. (2021), doi: 10.1016/j.scs.2020.102491.

52. P. Palensky and D. Bruckner, "Anticipative virtual storage power plants," in 2009 35th Annual Conference of IEEE Industrial Electronics, Nov. (2009), pp. 3571-3574. doi: 10.1109/IECON.2009.5415158. 
53. R.-C. Dai, B. Zhao, X.-D. Zhang, J.-W. Yu, B. Fan, and B. Liu, “Joint Virtual Energy Storage Modeling with Electric Vehicle Participation in Energy Local Area Smart Grid," Complexity, vol. 2020, p. e3102729, Oct. (2020), doi: 10.1155/2020/3102729.

54. E. Oh, "Reinforcement-Learning-Based Virtual Energy Storage System Operation Strategy for Wind Power Forecast Uncertainty Management," Appl. Sci., vol. 10, no. 18, Art. no. 18, Jan. (2020), doi: 10.3390/app10186420.

55. H. Ning and H. Liu, "Cyber-physical-social-thinking space based science and technology framework for the Internet of Things," Sci. China Inf. Sci., vol. 58, no. 3, pp. 1-19, Mar. (2015), doi: 10.1007/s11432-014-5209-2.

56. R. K. Lenka et al., "Building Scalable Cyber-Physical-Social Networking Infrastructure Using IoT and Low Power Sensors," IEEE Access, vol. 6, pp. 3016230173, (2018), doi: 10.1109/ACCESS.2018.2842760.

57. H. Ning and H. Liu, "Cyber-Physical-Social Based Security Architecture for Future Internet of Things," Adv. Internet Things, vol. 02, no. 01, Art. no. 01, Jan. (2012), doi: 10.4236/ait.2012.21001.

58. H. Ning, H. Liu, J. Ma, L. T. Yang, and R. Huang, "Cybermatics: Cyber-physicalsocial-thinking hyperspace based science and technology," Future Gener. Comput. Syst., vol. 56, pp. 504-522, Mar. (2016), doi: 10.1016/j.future.2015.07.012.

59. H. Muccini and M. T. Moghaddam, "IoT Architectural Styles," in Software Architecture, Cham, (2018), pp. 68-85. doi: 10.1007/978-3-030-00761-4_5.

60. A. A. Zaidan et al., "A survey on communication components for IoT-based technologies in smart homes," Telecommun. Syst., vol. 69, no. 1, pp. 1-25, Sep. (2018), doi: 10.1007/s11235-018-0430-8.

61. M. T. Lazarescu, "Wireless Sensor Networks for the Internet of Things: Barriers and Synergies," in Components and Services for IoT Platforms: Paving the Way for IoT Standards, G. Keramidas, N. Voros, and M. Hübner, Eds. Cham: Springer International Publishing, (2017), pp. 155-186. doi: 10.1007/978-3-319-42304-3_9.

62. G. Hafeez et al., "Efficient Energy Management of IoT-Enabled Smart Homes Under Price-Based Demand Response Program in Smart Grid," Sensors, vol. ), no. 11, Art. no. 11, Jan. (2020), doi: 10.3390/s20113155.

63. L. Barbierato et al., "A Distributed IoT Infrastructure to Test and Deploy Real-Time Demand Response in Smart Grids," IEEE Internet Things J., vol. ), no. 1, pp. 11361146, Feb. (2019), doi: 10.1109/JIOT.2018.2867511.

64. C. Pop, T. Cioara, M. Antal, I. Anghel, I. Salomie, and M. Bertoncini, "Blockchain Based Decentralized Management of Demand Response Programs in Smart Energy Grids," Sensors, vol. 18, no. 1, Art. no. 1, Jan. (2018), doi: 10.3390/s18010162.

65. J. W. Heron, J. Jiang, H. Sun, V. Gezerlis, and T. Doukoglou, "Demand-Response Round-Trip Latency of IoT SmartGrid Network Topologies," IEEE Access, vol. 6, pp. 22930-22937, (2018), doi: 10.1109/ACCESS.2018.2831254.

66. A. K. Sultania, F. Mahfoudhi, and J. Famaey, "Real-Time Demand Response Using NB-IoT," IEEE Internet Things J., vol. 7, no. 12, pp. 11863-11872, Dec. (2020), doi: 10.1109/JIOT.2020.3004390.

67. P. Zhou et al., "Research on Mining of Transmission Grid Assets of Heterogeneous System Based on Digital Twin," in 2020 IEEE 4th Conference on Energy Internet and Energy System Integration (EI2), Wuhan, China, Oct. (2020), pp. 3051-3056. doi: 10.1109/EI250167.2020.9346945.

68. E. O'Dwyer, I. Pan, R. Charlesworth, S. Butler, and N. Shah, "Integration of an energy management tool and digital twin for coordination and control of multi-vector smart energy systems," Sustain. Cities Soc., vol. 62, p. 102412, Oct. (2020), doi: $10.1016 /$ j.scs.2020.102412. 
69. W. Tushar et al., "Internet of Things for Green Building Management: Disruptive Innovations Through Low-Cost Sensor Technology and Artificial Intelligence," IEEE Signal Process. Mag., vol. 35, no. 5, pp. 100-110, Sep. (2018), doi: 10.1109/MSP.2018.2842096.

70. K. G. Dangi and S. P. Panda, "Challenges in Wireless Body Area Network-A survey," in 2014 International Conference on Reliability Optimization and Information Technology (ICROIT), Feb. (2014), pp. 204-207. doi: 10.1109/ICROIT.2014.6798337.

71. S. M. A. Group et al., "Internet of Things (IoT): A Literature Review," J. Comput. Commun., vol. 03, no. 05, Art. no. 05, (2015), doi: 10.4236/jcc.2015.35021.

72. A. Čolaković and M. Hadžialić, "Internet of Things (IoT): A review of enabling technologies, challenges, and open research issues," Comput. Netw., vol. 144, pp. 1739, Oct. (2018), doi: 10.1016/j.comnet.2018.07.017.

73. A. Rasheed, O. San, and T. Kvamsdal, "Digital Twin: Values, Challenges and Enablers From a Modeling Perspective," IEEE Access, vol. 8, pp. 21980-22012, (2020), doi: 10.1109/ACCESS.2020.2970143.

74. M. Zhou, J. Yan, and D. Feng, "Digital twin framework and its application to power grid online analysis," CSEE J. Power Energy Syst., vol. 5, no. 3, pp. 391-398, Sep. (2019), doi: 10.17775/CSEEJPES.2018.01460.

75. Y.-L. Huang and W.-L. Sun, "An AHP-Based Risk Assessment for an Industrial IoT Cloud," in 2018 IEEE International Conference on Software Quality, Reliability and Security Companion (QRS-C), Jul. (2018), pp. 637-638. doi: 10.1109/QRSC.2018.00112.

76. P. Ganguly, "Selecting the right IoT cloud platform," in 2016 International Conference on Internet of Things and Applications (IOTA), Jan. (2016), pp. 316-320. doi: 10.1109/IOTA.2016.7562744.

77. V. Malik and S. Singh, "Cloud, Big Data IoT: Risk Management," in 2019 International Conference on Machine Learning, Big Data, Cloud and Parallel Computing (COMITCon), Feb. (2019), pp. 258-262. doi: 10.1109/COMITCon.2019.8862445.

78. A. L'Heureux, K. Grolinger, H. F. Elyamany, and M. A. M. Capretz, "Machine Learning With Big Data: Challenges and Approaches," IEEE Access, vol. 5, pp. 77767797, (2017), doi: 10.1109/ACCESS.2017.2696365.

79. A. Blum and K. Stangl, "Recovering from Biased Data: Can Fairness Constraints Improve Accuracy?," ArXiv191201094 Cs Stat, Dec. (2019), Accessed: Jun. 11, 2021. Online. Available: http://arxiv.org/abs/1912.01094

80. W. Blanzeisky and P. Cunningham, "Algorithmic Factors Influencing Bias in Machine Learning," ArXiv210414014 Cs Stat, Apr. (2021), Accessed: Jun. 11, 2021. Online. Available: http://arxiv.org/abs/2104.14014

81. J. Gu and D. Oelke, "Understanding Bias in Machine Learning," ArXiv190901866 Cs Stat, Sep. (2019), Accessed: Jun. 11, 2021. Online. Available: http://arxiv.org/abs/1909.01866

82. M. Grieves, "Digital twin: manufacturing excellence through virtual factory replication," White Pap., vol. 1, pp. 1-7, (2014).

83. W. Michael, "Grieves Digital Twin: Manufacturing Excellence through Virtual Factory Replication-LLC," (2014).

84. F. Tao and M. Zhang, "Digital Twin Shop-Floor: A New Shop-Floor Paradigm Towards Smart Manufacturing," IEEE Access, vol. 5, pp. 20418-20427, (2017), doi: 10.1109/ACCESS.2017.2756069.

85. Q. Qi and F. Tao, "Digital Twin and Big Data Towards Smart Manufacturing and Industry 4.0: 360 Degree Comparison," IEEE Access, vol. 6, pp. 3585-3593, (2018), doi: 10.1109/ACCESS.2018.2793265. 
86. E. J. Tuegel, A. R. Ingraffea, T. G. Eason, and S. M. Spottswood, "Reengineering Aircraft Structural Life Prediction Using a Digital Twin,” Int. J. Aerosp. Eng., vol. 2011, p. e154798, Oct. (2011), doi: 10.1155/2011/154798.

87. S. Moghadaszadeh Bazaz, "Digital twin and its application on plywood production line,” (2019), Accessed: Jun. 13, 2021. Online. Available: https://lutpub.lut.fi/handle/10024/159166

88. X. Wang, L. Li, Y. Yuan, P. Ye, and F.-Y. Wang, "ACP-based social computing and parallel intelligence: Societies 5.0 and beyond," CAAI Trans. Intell. Technol., vol. 1, no. 4, pp. 377-393, Oct. (2016), doi: 10.1016/j.trit.2016.11.005.

89. B. Gockel, A. Tudor, M. Brandyberry, R. Penmetsa, and E. Tuegel, "Challenges with Structural Life Forecasting Using Realistic Mission Profiles," in 53rd AIAA/ASME/ASCE/AHS/ASC Structures, Structural Dynamics and Materials Conference, American Institute of Aeronautics and Astronautics. doi: 10.2514/6.20121813.

90. E. Tuegel, "The Airframe Digital Twin: Some Challenges to Realization," in 53rd AIAA/ASME/ASCE/AHS/ASC Structures, Structural Dynamics and Materials Conference, American Institute of Aeronautics and Astronautics. doi: 10.2514/6.20121812.

91. M. Ciavotta, M. Alge, S. Menato, D. Rovere, and P. Pedrazzoli, "A Microservicebased Middleware for the Digital Factory," Procedia Manuf., vol. 11, pp. 931-938, (2017), doi: 10.1016/j.promfg.2017.07.197.

92. G. Chen, P. Wang, B. Feng, Y. Li, and D. Liu, "The framework design of smart factory in discrete manufacturing industry based on cyber-physical system," Int. J. Comput. Integr. Manuf., vol. 33, no. 1, pp. 79-101, (2020), doi: 10.1080/0951192X.2019.1699254.

93. R. Rosen, G. von Wichert, G. Lo, and K. D. Bettenhausen, "About The Importance of Autonomy and Digital Twins for the Future of Manufacturing," IFAC-Pap., vol. 48, no. 3, pp. 567-572, Jan. (2015), doi: 10.1016/j.ifacol.2015.06.141.

94. J. Lee, E. Lapira, B. Bagheri, and H. Kao, "Recent advances and trends in predictive manufacturing systems in big data environment," Manuf. Lett., vol. 1, no. 1, pp. 38-41, Oct. (2013, doi: 10.1016/j.mfglet.2013.09.005.

95. M. Grieves and J. Vickers, "Digital twin: Mitigating unpredictable, undesirable emergent behavior in complex systems," in Transdisciplinary Perspectives on Complex Systems: New Findings and Approaches, (2016), pp. 85-113. doi: 10.1007/978-3-31938756-7_4.

96. E. Negri, L. Fumagalli, and M. Macchi, "A Review of the Roles of Digital Twin in CPS-based Production Systems,” Procedia Manuf., vol. 11, pp. 939-948, Jan. (2017), doi: 10.1016/j.promfg.2017.07.198.

97. T. H.-J. Uhlemann, C. Lehmann, and R. Steinhilper, "The Digital Twin: Realizing the Cyber-Physical Production System for Industry 4.0," Procedia CIRP, vol. 61, pp. 335340, Jan. (2017), doi: 10.1016/j.procir.2016.11.152.

98. T. Bauernhansl, WGP-Standpunkt Industrie 4.0. WGP, Wissenschaftliche Gesellschaft für Produktionstechnik, (2016.

99. D. Ivanov, "Predicting the impacts of epidemic outbreaks on global supply chains: A simulation-based analysis on the coronavirus outbreak (COVID-19/SARS-CoV-2) case," Transp. Res. Part E Logist. Transp. Rev., vol. 136, (2020), doi: 10.1016/j.tre.2020.101922.

100.A. Rezaei Aderiani, K. Wärmefjord, and R. Söderberg, "Evaluating different strategies to achieve the highest geometric quality in self-adjusting smart assembly lines," Robot. Comput.-Integr. Manuf., vol. 71, (2021) doi: 10.1016/j.rcim.2021.102164. 
101.G. B. Ozturk, "Digital Twin Research in the AECO-FM Industry," J. Build. Eng., vol. 40, p. 102730, Aug. (2021) doi: 10.1016/j.jobe.2021.102730.

102.P. Bosch-Sijtsema, C. Claeson-Jonsson, M. Johansson, and M. Roupe, "The hype factor of digital technologies in AEC," Constr. Innov., vol. ahead-of-print, no. aheadof-print, Jan. (2021) doi: 10.1108/CI-01-2020-0002.

103.Q. Lu, X. Xie, A. K. Parlikad, and J. M. Schooling, "Digital twin-enabled anomaly detection for built asset monitoring in operation and maintenance," Autom. Constr., vol. 118, p. 103277, Oct. (2020), doi: 10.1016/j.autcon.2020.103277.

104.J. Zhang, L. Zi, Y. Hou, M. Wang, W. Jiang, and D. Deng, "A Deep Learning-Based Approach to Enable Action Recognition for Construction Equipment," Adv. Civ. Eng., vol. 2020, p. e8812928, Nov. (2020), doi: 10.1155/2020/8812928.

105.J. Zhang, L. Zhao, G. Ren, H. Li, and X. Li, “Special Issue 'Digital Twin Technology in the AEC Industry," Adv. Civ. Eng., vol. 2020, p. e8842113, Nov. (2020), doi: $10.1155 / 2020 / 8842113$.

106.E. Shahat, C. T. Hyun, and C. Yeom, "City digital twin potentials: A review and research agenda," Sustain. Switz., vol. 13, no. 6, (2021) doi: 10.3390/su13063386.

107.A. Tezel, E. Papadonikolaki, I. Yitmen, and P. Hilletofth, "Preparing construction supply chains for blockchain technology: An investigation of its potential and future directions," Front. Eng. Manag., vol. 7, no. 4, pp. 547-563, Dec. (2020), doi: 10.1007/s42524-020-0110-8.

108.S. H. Khajavi, N. H. Motlagh, A. Jaribion, L. C. Werner, and J. Holmstrom, "Digital Twin: Vision, benefits, boundaries, and creation for buildings," IEEE Access, vol. 7, pp. 147406-147419, (2019), doi: 10.1109/ACCESS.2019.2946515.

109.E. VanDerHorn and S. Mahadevan, "Digital Twin: Generalization, characterization and implementation," Decis. Support Syst., vol. 145, (2021) doi: 10.1016/j.dss.2021.113524.

110. "IOP Conference Series: Materials Science and Engineering,” 2019, vol. 618, no. 1.

111.Z. Cheng and V. E. Kuzmichev, "Digital twin and men's underwear design," (2018), vol. 459, no. 1. doi: 10.1088/1757-899X/459/1/012075.

112.P. P. Oliveira, "Digital twin development for airport management," J. Airpt. Manag., vol. 14, no. 3, pp. 246-259, (2020.

113.E. G. Kaigom and J. Rosmann, "Value-Driven Robotic Digital Twins in CyberPhysical Applications," IEEE Trans. Ind. Inform., vol. 17, no. 5, pp. 3609-3619, (2021) doi: 10.1109/TII.2020.3011062.

114.M. Matulis and C. Harvey, "A robot arm digital twin utilising reinforcement learning," Comput. Graph. Pergamon, vol. 95, pp. 106-114, (2021) doi: 10.1016/j.cag.2021.01.011.

115.S. Nativi, P. Mazzetti, and M. Craglia, "Digital ecosystems for developing digital twins of the earth: The destination earth case," Remote Sens., vol. 13, no. 11, (2021) doi: $10.3390 / \mathrm{rs} 13112119$.

116. "Ural Environmental Science Forum 'Sustainable Development of Industrial Region', UESF 2021," (2021) vol. 258.

117.R. Snijders, P. Pileggi, J. Broekhuijsen, J. Verriet, M. Wiering, and K. Kok, "Machine learning for digital twins to predict responsiveness of cyber-physical energy systems," (2020). doi: 10.1109/MSCPES49613.2020.9133695.

118.Z. Hameed, Y. S. Hong, Y. M. Cho, S. H. Ahn, and C. K. Song, "Condition monitoring and fault detection of wind turbines and related algorithms: A review," Renew. Sustain. Energy Rev., vol. 13, no. 1, pp. 1-39, (2009.

119.P. A. Fokaides et al., "Research challenges and advancements in the field of sustainable energy technologies in the built environment," Sustain. Switz., vol. 12, no. 20, pp. 1-20, (2020), doi: 10.3390/su12208417. 
120.C. J. Valant, J. D. Wheaton, M. G. Thurston, S. P. McConky, and N. G. Nenadic, "Evaluation of 1D CNN Autoencoders for Lithium-ion Battery Condition Assessment Using Synthetic Data," Annu. Conf. PHM Soc., vol. 11, no. 1, Art. no. 1, Sep. (2019), doi: 10.36001/phmconf.2019.v11i1.876.

121.A. Kummerow, C. Monsalve, D. Rösch, K. Schäfer, and S. Nicolai, "Cyber-physical data stream assessment incorporating Digital Twins in future power systems," in 2020 International Conference on Smart Energy Systems and Technologies (SEST), Sep. (2020), pp. 1-6. doi: 10.1109/SEST48500.2020.9203270.

122.Y. Yang, X. Li, Z. Yang, Q. Wei, N. Wang, and L. Wang, "The application of cyber physical system for thermal power plants: Data-driven modeling," Energies, vol. 11, no. 4, (2018), doi: 10.3390/en11040690.

123.Y. Cui, F. Xiao, W. Wang, X. He, C. Zhang, and Y. Zhang, "Digital Twin for Power System Steady-state Modelling, Simulation, and Analysis," in 2020 IEEE 4th Conference on Energy Internet and Energy System Integration (EI2), Nov. (2020), pp. 1233-1238. doi: 10.1109/EI250167.2020.9346850.

124.H. Pan, Z. Dou, Y. Cai, W. Li, X. Lei, and D. Han, "Digital Twin and Its Application in Power System," in 2020 5th International Conference on Power and Renewable Energy (ICPRE), Sep. (2020), pp. 21-26. doi: 10.1109/ICPRE51194.2020.9233278.

125.M. Atalay and P. Angin, "A Digital Twins Approach to Smart Grid Security Testing and Standardization," in 2020 IEEE International Workshop on Metrology for Industry 4.0 IoT, Jun. (2020), pp. 435-440. doi: 10.1109/MetroInd4.0IoT48571.2020.9138264.

126.A. E. Onile, R. Machlev, E. Petlenkov, Y. Levron, and J. Belikov, "Uses of the digital twins concept for energy services, intelligent recommendation systems, and demand side management: A review," Energy Rep., vol. 7, pp. 997-1015, Nov. (2021) doi: 10.1016/j.egyr.2021.01.090.

127.N. Tzanis, N. Andriopoulos, A. Magklaras, E. Mylonas, M. Birbas, and A. Birbas, "A Hybrid Cyber Physical Digital Twin Approach for Smart Grid Fault Prediction," in 2020 IEEE Conference on Industrial Cyberphysical Systems (ICPS), Jun. (2020), vol. 1, pp. 393-397. doi: 10.1109/ICPS48405.2020.9274723.

128.X. Xie, A. K. Parlikad, and R. S. Puri, “A Neural Ordinary Differential Equations Based Approach for Demand Forecasting within Power Grid Digital Twins," in 2019 IEEE International Conference on Communications, Control, and Computing Technologies for Smart Grids (SmartGridComm), Oct. (2019), pp. 1-6. doi: 10.1109/SmartGridComm.2019.8909789.

129.X. He, Q. Ai, R. C. Qiu, and D. Zhang, "Preliminary Exploration on Digital Twin for Power Systems: Challenges, Framework, and Applications," ArXiv190906977 Eess Stat, Sep. (2019), Accessed: Mar. 11, 2021. Online. Available: http://arxiv.org/abs/1909.06977

130.J. Huang, L. Zhao, F. Wei, and B. Cao, "The Application of Digital Twin on Power Industry," IOP Conf. Ser. Earth Environ. Sci., vol. 647, p. 012015, Jan. (2021) doi: 10.1088/1755-1315/647/1/012015.

131.P. Pileggi, J. Verriet, J. Broekhuijsen, C. van Leeuwen, W. Wijbrandi, and M. Konsman, "A Digital Twin for Cyber-Physical Energy Systems," in 2019 7th Workshop on Modeling and Simulation of Cyber-Physical Energy Systems (MSCPES), Apr. (2019), pp. 1-6. doi: 10.1109/MSCPES.2019.8738792.

132.T. I. Strasser et al., "An overview of trends and developments of internet of things applied to industrial systems," in Proceedings: IECON - Annu. Conf. IEEE Ind. Electron. Soc., (2018), pp. 2853-2860. doi: 10.1109/IECON.2018.8591431.

133.D. Tucker, P. Pezzini, and K. M. Bryden, "Cyber-physical systems: A new paradigm for energy technology development," in ASME Power Div Publ POWER, (2018), vol. 1. doi: 10.1115/POWER2018-7315. 
134.L. V. Massel and A. G. Massel, "Development of Digital Twins and Digital Shadows of Energy Objects and Systems Using Scientific Tools for Energy Research," in E3S Web Conf., (2020), vol. 209. doi: 10.1051/e3sconf/202020902019.

135.A. Saad, S. Faddel, T. Youssef, and O. A. Mohammed, "On the Implementation of IoT-Based Digital Twin for Networked Microgrids Resiliency Against Cyber Attacks," IEEE Trans. Smart Grid, vol. 11, no. 6, pp. 5138-5150, Nov. (2020), doi: 10.1109/TSG.2020.3000958.

136.A. Benigni, T. Strasser, G. De Carne, M. Liserre, M. Cupelli, and A. Monti, "RealTime Simulation-Based Testing of Modern Energy Systems: A Review and Discussion," IEEE Ind. Electron. Mag., vol. 14, no. 2, pp. 28-39, (2020), doi: 10.1109/MIE.2019.2957996.

137.N. Conway and A. Hainoun, "Regional energy demand analysis portal (REDAP) digitalisation: Enabling better government decision-making in the building \& transport sectors," in IOP Conf. Ser. Earth Environ. Sci., vol. 588, no. 3. (2020), doi: 10.1088/1755-1315/588/3/032008. 